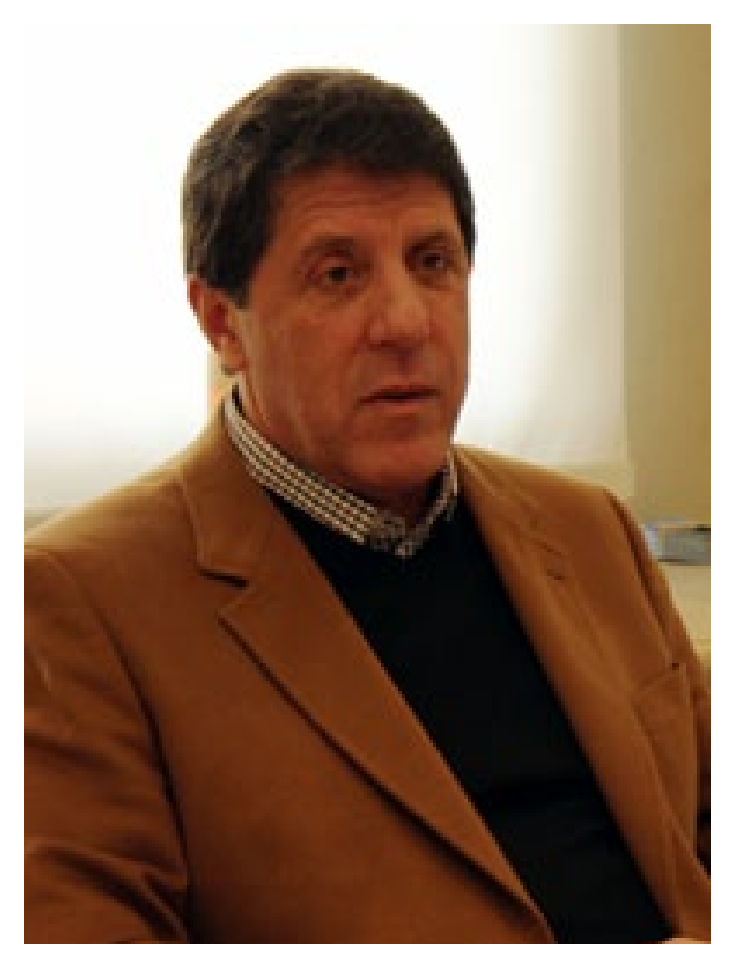

Entrevistadores

Maria Aparecida Ferrari

Arquimedes Pessoni

\section{Foto}

Renata Biagioni Wrobleski

\section{Dr. David Uip}

- Médico, com mestrado e doutorado em Doenças Infecciosas e Parasitárias

- $\quad$ Livre-docente em Toxoplasmose em Pacientes Submetidos a Transplante Cardíaco, pela

Faculdade de Medicina da Universidade de São Paulo (FM-USP)

- $\quad$ Diretor técnico de Serviço do Instituto de Infectologia Emílio Ribas

- Trajetória profissional ligada à área acadêmica e a clínica médica

- Foi médico de importantes personalidades da política brasileira, entre elas o ex-governador de São Paulo Mário Covas

\title{
Comunicação médico-paciente
}

Doctor-patient relationship

Comunicación médico-paciente

\section{Entrevista}

David Uip 
ntre seus compromissos no Hospital Emilio Ribas e as consultas na clínica médica, o Prof.

$\mathbf{E}_{\mathrm{D}}$ Dr. David E. Uip, uma das maiores autoridades sobre infectologia do Brasil, nos recebeu para uma entrevista. Chamou-nos a atenção seu interesse pela comunicação e como ele a tem incorporado na relação médico-paciente. Sua experiência acadêmica, bem como em clínica médica, gestão de hospitais e atendimento de personalidades de vários setores da sociedade, se irradia na sua conversa e nos exemplos que nos deu para as nossas perguntas. Para sintetizar, Dr. Uip é, sobretudo, um profissional que, com sua experiência e seus conhecimentos, conseguiu angariar credibilidade nos meios de comunicação e em outros setores da sociedade. Sua opinião é respeitada e aceita, o que faz dele um comunicador por natureza.

Organicom - Como o senhor define a comunicação?

Dr. David Uip - A comunicação é fundamental. Tanto que há muitos anos eu trabalho intuitivamente com isso. Eu descobri a importância e achei que era um caminho que deveria ser seguido. Tanto a comunicação interna, como a comunicação externa. Como diretor do Hospital Emílio Ribas, percebo a dificuldade de uma comunicação ampla com todos os públicos.

Quanto à comunicação interna, na minha gestão, desenvolvi, com um grupo de representantes de todas as áreas, uma série de ações, como reuniões com o corpo clínico e com todos os funcionários do hospital, objetivando capilarizar a informação, uma vez que estamos falando de um número enorme de funcionários no complexo hospitalar.

Temos duas jornalistas, ligadas à Secretaria do Estado da Saúde, que me assessoram para transpor a dificuldade de comunicação com diferentes grupos de públicos. Noto que o grande problema é fazer chegar às bases a informação que foi decidida nas reuniões de colegiado. Dessa forma, acredito que a comunicação é um processo que afeta diretamente o meu trabalho.

\section{Quanto à comunicação interna, realizamos reuniões com o corpo clínico e com todos os funcionários do hospital, objetivando capilarizar a informação}




\section{Somos técnicos extremamente especializados e, portanto, temos obrigação de comunicar tudo aquilo que entendemos que seja necessário}

Por outro lado, a comunicação externa é uma obrigação nossa, embora seja o grande temor da maioria dos médicos. Médico não gosta de falar com jornalistas. $E$ eu sempre digo que nós somos técnicos extremamente especializados e, portanto, temos obrigação de comunicar tudo aquilo que entendemos que seja necessário. Se nós não falarmos, quem vai falar por nós? A nossa informação é segura e respaldada cientificamente. Nenhum de nós fala se não estiver absolutamente atualizado.

Estamos vivendo duas situações interessantes. A primeira é que acabaram de criar uma pandemia do H1N1. De onde os meios de comunicação tiraram isso eu não tenho a menor ideia! A verdade é que nós não estamos com uma pandemia. O segundo caso está relacionado com a invenção de um medicamento, uma pílula que vai acabar com a aids no mundo. É uma pílula que, caso aprovada, é para ser distribuída para as populações expostas. Portanto, precisamos parar e pensar: uma coisa é você analisar um trabalho científico, que, neste caso, foi muito bem feito; a outra é transformar a conclusão em política pública. Como eu posso imaginar quem são as populações expostas? Onde elas se encontram? Então, eu não estou lidando com uma população de indivíduos doentes, estou lidando com uma população de indivíduos expostos. E o que é ser exposto?

O médico tem que se posicionar. Falar o que as pessoas querem ouvir é fácil. Mas, a meu ver, o lado da comunicação que é importante é o da comunicação técnica. Acho que é vital e é obrigação do profissional da saúde ter conhecimento dela.

\section{A meu ver, o lado da comunicação que é im- portante é o da comunicação técnica. Acho que é vital e é obrigação do profissional da saúde ter conhecimento dela}


Por último, o outro lado da comunicação que temos que enfrentar é a comunicação de crise na saúde, pois o porta-voz, no caso o médico, tem que ter credibilidade. No caso da pandemia H1N1, em 2009, eu fui o porta-voz e dei entrevista até para a televisão da Coreia do Sul, para o mundo inteiro, porque era algo que estava acontecendo no Brasil e precisava ser comunicado. Foi um processo interessante, pois meu papel como porta-voz era explicar a crise e acalmar a opinião pública.

A outra situação, que também é muito interessante, é ser porta-voz institucional em situações que são eventuais, mas extremamente importantes. A primeira que eu vivi foi na doença do político Tancredo Neves e na qual o porta-voz era um jornalista. A rotina era a seguinte: a equipe médica comunicava ao jornalista o que estava fazendo e ele elaborava a informação para a imprensa. Até aí tudo bem. Só que as informações nem sempre eram entendidas e aí chegavam os problemas de interpretação.

Esse processo ficou muito claro pra mim na época da doença do governador de São Paulo Mário Covas. Além de eu ser médico dele, ele determinou que eu falasse em nome dele, da família e do governo. E para mim isso foi uma quebra de paradigma. Foi a primeira vez que eu vi um político que quis que as coisas fossem faladas claramente, sem esconder nada. Então, nós criamos um sistema de informação no qual nós - médicos - nos reuníamos com o governador e com a assessora de comunicação e preparávamos um boletim que era comunicado por mim ou por outro membro da equipe e nos colocávamos à disposição da imprensa para as dúvidas. Com isso, acabamos com o off da imprensa. Claro que houve alguns desvios, mas no geral as informações transmitidas pela mídia estavam corretas. A imprensa e, consequentemente, o povo brasileiro foram informados absolutamente de tudo, como era o desejo do governador Mário Covas.

\section{Organicom - Então para o senhor a comunicação é...}

Dr. David Uip - ... também uma arte. Desde que entrei no Hospital Emílio Ribas, há três anos e meio, tenho feito muito para que outros médicos falem pela instituição. Assumi um hospital que precisa de muitos investimentos. Era um hospital bem conhecido pela sociedade, mas com grandes dificuldades de recursos financeiros e humanos. Minha estratégia foi mostrar a história desse hospital. E essa história tem que ser contada direito. Então, hoje, no Emílio Ribas vários médicos falam para a imprensa de assuntos técnicos. Isso está sendo muito incentivado.

Eu acredito que consegui avançar muito e até consegui convencer que precisava de assessoria. Tenho duas jornalistas que cuidam da assessoria de imprensa e de projetos específicos. 


\section{Se existem deficiências dos médicos para en- tender o processo de comunicação, os jornalis- tas também têm um conhecimento incipiente em termos de treinamento para a área da saúde}

Se existem problemas de deficiências dos médicos para entender o processo de comunicação, os jornalistas também têm um conhecimento incipiente em termos de treinamento para a área da saúde. Aí temos outro desafio. Você vai ser entrevistado e, muitas vezes, os veículos de comunicação não enviam um jornalista especializado. E então temos que explicar para o jornalista até mesmo o que ele deve perguntar...

Organicom - Da comunicação no dia a dia vamos passar para o currículo das escolas de saúde (Medicina, Enfermagem, Fisioterapia etc.). A ser ver, como a comunicação deveria ser tratada na área da saúde?

Dr. David Uip - Existem muitas falhas no currículo do curso de Medicina, em especial. A comunicação não existe como disciplina na grade curricular. Eu fico pensando na importância que tem para um médico fazer a gestão do próprio consultório e com isso aprender a ser um empreendedor. Sou professor da Faculdade de Medicina do ABC e tenho usado uma estratégia, que é conseguir parceiros para os meus projetos sociais. Montei um prédio inteiro, totalmente com doações. Agora, o indivíduo doou por quê? Porque tenho credibilidade. Ele sabe que o recurso vai ser bem utilizado, controlado, mas tem que conhecer a mim ou a outro colega médico que tenha credibilidade. Então, tudo isso é um processo de relacionamento conquistado ao longo do tempo, com comunicação e produtos tangíveis e de qualidade.

Organicom - Além dos veículos tradicionais, agora contamos com as redes sociais, que têm causado certo "furor" nas mais diferentes áreas do conhecimento. E o Dr. Google: ajuda ou atrapalha? 
Dr. David Uip - Eu acho que, quanto mais informadas estiverem as pessoas, melhor. Agora, sempre deixo claro para o meu paciente que ele nunca vai saber mais do que eu em termos de medicina. Nem ele e nem o Google. Tenho pacientes que entram no Google, identificam trabaIhos científicos pertinentes e me mandam com um bilhetinho: "caso o senhor não tenha lido, aqui está a informação". Conclusão: eles me capacitam e não me sinto ofendido. Prefiro trabalhar com pessoas informadas a lidar com pacientes não entendem o que está acontecendo.

Organicom - Há algumas décadas, não existia o computador. Então, o que o médico dissesse ao paciente estava ok. Hoje o paciente chega em casa e vai buscar o remédio, a palavra-chave. Qual é o risco disso?

Dr. David Uip - O risco é o quanto isso atrapalha a pessoa. A mim não atrapalha em nada. Por exemplo: o indivíduo acaba de saber que está com aids. Ele vai ler tudo que puder e então, na maioria dos casos, enlouquece. Ele chega ao meu consultório transtornado, porque não teve como filtrar as informações e isso foi ruim para ele. Meu trabalho é colocar as coisas nos seus devidos lugares. Mas, pensemos no que ele sofreu até chegar aqui...

Organicom - Como vimos, muitos pacientes buscam informações sobre doenças, sintomas e remédios. Já existem grupos de pessoas que sofrem de uma determinada doença e formam grupos de autoajuda. O senhor acredita que os grupos ajudam o paciente na busca de informação sobre remédios ou doenças?

Dr. David Uip - Uma das reivindicações dos meus pacientes é para eu criar grupos nos quais eles possam conversar. Mas é um grande desafio. Primeiro, vou precisar de um moderador. Aí, na relação do HIV, tenho que ter pessoas com determinadas semelhanças, sejam culturais ou intelectuais, porque, se o grupo for muito heterogêneo, existe grande possibilidade de domínio de uma pessoa sobre os demais. Além disso, em fases de evolução da doença semelhantes, se pego um indivíduo que é HIV assintomático e um indivíduo que é HIV há vinte anos, lipodistrófico, este olha e fala "eis o meu futuro", o que não é necessariamente verdadeiro.

\section{Sempre deixo claro para o meu paciente que ele nunca vai saber mais do que eu em termos de medicina. Nem ele e nem o Google}




\section{Um computador não vai substituir a relação médico-paciente. Essa relação tem que ser cultivada, enriquecida. E isso só se dá no contato pessoal}

Então, até o momento, estou hesitando porque temo que, em vez de criar uma solução, vou criar mais um problema. É preciso ser muito cuidadoso na composição do grupo e tem que haver pessoas moderadoras com muita experiência. Não se sabe aonde vai parar essa conversa e até onde vai ajudar ou prejudicar. No caso do HIV, não é simples. É uma doença com muitos preconceitos e as redes sociais têm o "anonimato". Não se sabe com quem se está falando. Então, eu temo por quem vai acessar justamente em um período de vulnerabilidade física e emocional.

Organicom - O senhor acredita que a comunicação entre médicos, governantes e pacientes vai mudar com a chegada das redes sociais?

Dr. David Uip - O jornal O Estado de S. Paulo publicou, no dia 17 de julho de 2012, um artigo escrito pelo Dr. Antônio Carlos Lopes. Ele usas frases dele que até parecem ser minhas. Muitas coisas que ele escreveu eu falo há muitos anos, principalmente no que se refere ao relacionamento médico-paciente.

Por exemplo: você vem aqui, eu fico olhando para você. Primeiro, quando você entra, tem que ser tratado afetivamente, o que é muito curioso. Você dá a mão, um abraço e quebra o gelo na primeira hora. Segundo, você é de um jeito e paciente de outro. Minha conversa tem que estar adequada com a faixa etária de meu paciente. Então, esse discurso tem que ser elaborado para cada um de meus pacientes. Na verdade, eu tenho que ter essa pluralidade para conseguir ter acesso às informações e aos sintomas que o paciente vai contar. Há outra coisa muito curiosa: médico tem que saber ouvir, o que é difícil. E, mais, tem que ouvir o que não está sendo falado, porque por trás de conversas existem outras coisas que, se ele não for muito atento e perspicaz, não as ouve. Então, isto só se dá de um jeito: por meio do contato. Eu sempre digo que um computador de última geração não vai substituir a relação médico-paciente. E esse é o ponto fundamental. Essa relação tem que ser cultivada, enriquecida, e isso só se dá no contato pessoal, nada vai substituir isso. 
Organicom - Como manter esse relacionamento que o senhor afirma ser tão importante quando no Brasil o sistema de saúde, seja público ou privado, exige que o médico atenda xis pacientes por dia? Onde fica a relação médico-paciente?

Dr. David Uip - Esse modelo está errado! No ambulatório do Hospital Emílio Ribas atendemos milhares de pessoas por dia. Mas eu exijo que cada médico atenda no máximo oito pacientes no período de quatro horas, seis retornos e dois novos. O médico tem que estar lá das 8 h00 às 12h00. É bom para todo mundo, especialmente para médico, que tem tempo para conversar com o paciente e fazer um diagnóstico mais acertado. Só temos que contar com uma variável que é o pagamento digno. Esse médico não pode ganhar mil reais por mês!

Organicom - As pesquisas mostram que um baixo número de médicos jovens opta pelas regiões Norte e Nordeste do Brasil, o que indica que a maioria prefere ficar nos grandes centros urbanos. $O$ que é preciso fazer para motivar esses jovens para investir sua carreira em outras regiões do país?

Dr. David Uip - Eu vivi uma experiência interessante, porque coordenei a área da saúde do Projeto Rondon e trabalhei muito tempo no Vale do Jequitinhonha, em Minas Gerais, e em Araçuaí, no interior do Pará. E há dez anos coordeno o projeto de assessoria de aids em Angola.

Acredito que o que mais prejudica o trabalho do médico é a falta de estrutura. Ele sabe que vai para um determinado lugar onde não vai ter condições de fazer o mínimo de seu trabalho. Hoje não dá para fazer medicina com boa vontade e estetoscópio, não dá mesmo! Eu identifico uma necessidade tecnológica no trabalho do médico. Não dá para abrir mão do mínimo. Sou do tempo em que foi inventado o ultrassom. Doía a barriga, não se sabia o que era, e então se operava o paciente para "descobrir". Hoje isso acabou. Então, um dos principais avanços é poder contar com uma infraestrutura mínima para uso individual. E a segunda necessidade é zelar para que o médico tenha possibilidades de capacitação permanente, de informação, de realinhamento do conhecimento. Ele tem que ter acesso a novas informações. Então, eu acho que não adianta mandar o médico para outras regiões e oferecer um bom salário. Ele precisa é de equipamentos e de atualização permanente.

\section{Tudo isso é um processo de relacionamento conquistado ao longo do tempo, com comuni- cação e produtos tangíveis e de qualidade}

